\title{
Characterization of Trichomonas vaginalis AP33 adhesin and cell surface interactive domains
}

\author{
J. A. Engbringt and J. F. Alderete \\ Author for correspondence: J. F. Alderete. Tel: +1 210567 3940. Fax: +1 2105676612 \\ e-mail: ALDERETE@UTHSCSA.EDU
}

Department of Microbiology, The University of Texas Health Science Center, 7703 Floyd Curl Drive, San Antonio, TX 78284-7758, USA

\begin{abstract}
Adherence to host target cells is a critical step in establishing infection with the sexually transmitted pathogen Trichomonas vaginalis. Four parasite surface proteins mediating attachment to vaginal epithelial cells have been identified. One surface protein, termed AP33, was characterized further to identify domains interactive with previously generated antibodies and with host surface sites. $\mathbf{N}$ - and $\mathbf{C}$-terminal deletion subclones were generated and tested for reactivity with both $\mathrm{mAb}$ and rabbit antiserum against AP33, and were also examined for their ability to bind to host cells. Surprisingly, the rabbit antiserum known to inhibit cytoadherence recognized an epitope(s) contained within 72 residues in the $\mathbf{N}$-terminal half of the protein. However, the mAb epitope was immunoreactive with a 28-amino-acid region near the C-terminus. Subsequent mapping of this region with overlapping peptides identified a nine-amino-acid sequence reactive with the mAb. Equally surprising, two domains interactive with host cell surfaces were identified at distinct parts of AP33: one in the N-terminal half of the protein, and the other within 24 residues in the C-terminal third. Further analysis of the C-terminal binding domain revealed that a peptide representing this area could inhibit T. vaginalis cytoadherence by $\mathbf{4 0} \%$.
\end{abstract}

Keywords: AP33 adhesin, cytoadherence, host-parasite, interactive domains, Trichomonas vaginalis

\section{INTRODUCTION}

Over 250 million people worldwide are infected with Trichomonas vaginalis, making this the most prevalent non-viral sexually transmitted disease agent (Quinn \& Krieger, 1990; World Health Organization, 1995). The parasite causes trichomonosis, which manifests as a vaginitis in women and a non-gonococcal, nonchlamydial urethritis in men, although most men are only transiently infected (Krieger et al., 1993). Women require drug intervention to eliminate this parasite (Müller et al., 1980), illustrating an adaptation to survival in the constantly changing environment of the human vagina. Adherence to host vaginal epithelial cells is essential for initiation and maintenance of infection by this mucosal parasite, and four trichomonad surface

\footnotetext{
†Present address: Craniofacial Development Biology and Regeneration Branch, National Institute of Dental Research, National Institutes of Health, Building 30, Bethesda, MD 20892-4370, USA.

Abbreviation: SCS, succinyl-COA synthetase.
}

proteins that mediate parasite cytoadherence to host cells have been identified (Alderete \& Garza, 1988; Arroyo et al., 1992).

Screening of a cDNA library with an $\mathrm{mAb}$ and rabbit antiserum against one of the adhesins, AP33, detected six immunoreactive clones (Arroyo et al., 1995). Analysis of the clones showed that they included three genes, each of which encoded a protein that was truncated at the N-terminus (Engbring \& Alderete, 1998). Although the DNA sequence was determined for all six clones, only the three that were near full-length and represented individual genes were examined in greater detail. Surprisingly, AP33 was found to have homology to the $\alpha$ subunit of succinyl-CoA synthetase ( $\alpha$-SCS), a metabolic enzyme. Unlike commercially obtained enzyme, the recombinant AP33 proteins bound to host cells and also inhibited native $T$. vaginalis AP33 binding. Although AP33 contained four consensus sequences involved in ATP/ADP and $\mathrm{Mg}^{2+}$ binding, as well as a conserved histidine residue, all critical for enzymic activity, none of the recombinant proteins autophosphorylated, a prerequisite for the $\alpha$-subunit enzymic function. 
The next logical step was to determine what regions of AP33 were antigenic and involved in adherence. Since the three recombinant AP33 proteins were immunocross-reactive, shared high sequence identity, and were each capable of adhesion (Engbring \& Alderete, 1998), only one was examined further. Proteins encoded by cDNAs and PCR-generated deletion mutants were tested for antigenic and adhesive function. A binding domain and the $\mathrm{mAb}$ epitope were identified.

\section{METHODS}

Micro-organisms and culture conditions. The fresh clinical $T$. vaginalis isolate (Arroyo et al., 1992), from which the cDNA library was made, was used for all assays. The trichomonads were grown at $37^{\circ} \mathrm{C}$ in Trypticase-yeast extract-maltose (TYM) medium supplemented with $10 \%$ heat-inactivated horse serum (Diamond, 1957). The parasites were harvested in the late-exponential phase of growth for use in the cytoadherence inhibition experiment. Escherichia coli strain HB101, containing the pcDNAII vector (Invitrogen) with or without insert DNA, was cultured in Luria-Bertani (LB) broth or on LB agar plates with $100 \mu \mathrm{g}$ ampicillin $\mathrm{ml}^{-1}$ (Sambrook et al., 1989).

The use of HeLa cells in monolayer culture as the in vitro model for cytoadherence studies has been detailed previously (Arroyo \& Alderete, 1989; Arroyo et al., 1992, 1993). Briefly, HeLa cells were grown to confluence in individual wells ( $\sim 8 \times 10^{4}$ cells) of 96-well plates in Dulbecco's modified Eagle's medium with $10 \%$ foetal bovine serum in $7.5 \% \mathrm{CO}_{2}$ atmosphere. The cells were washed twice with cold PBS (136.9 mM NaCl; $2.7 \mathrm{mM} \mathrm{KCl} ; 4.6 \mathrm{mM} \mathrm{Na}{ }_{2} \mathrm{HPO}_{4} ; 1.47 \mathrm{mM}$ $\mathrm{KH}_{2} \mathrm{PO}_{4} ; \mathrm{pH} 7 \cdot 0$ ) and fixed with $3 \%$ glutaraldehyde for $1 \mathrm{~h}$ at $4{ }^{\circ} \mathrm{C}$, followed by five washes with cold PBS. Reactive groups were blocked with $0.5 \mathrm{M}$ glycine in PBS for $18 \mathrm{~h}$ at $4^{\circ} \mathrm{C}$, washed three times with cold PBS, and stored at $4{ }^{\circ} \mathrm{C}$.

SDSPAGE and immunoblotting. Samples were boiled for $3 \mathrm{~min}$ in dissolving buffer $(62.5 \mathrm{mM}$ Tris $/ \mathrm{HCl}, \mathrm{pH} 6.2 ; 10 \%$ glycerol; $5 \%$ 2-mercaptoethanol; $0.001 \%$ bromophenol blue) prior to electrophoresis through $5 \%$ stacking and $10 \%$ separating gels (Laemmli, 1970). Gels were either stained with Coomassie brilliant blue or transferred electrophoretically to nitrocellulose (Bio-Rad) for immunoblotting (Towbin et al., 1979). Immunoblots were incubated with an $\mathrm{mAb}$ or rabbit antiserum generated against AP33 (Arroyo et al., 1992) or patient serum, followed by $1: 4000$ dilution of goat antimouse, anti-rabbit or anti-human IgG-alkaline phosphatase conjugates (Sigma), and were developed according to standard procedures (Sambrook et al., 1989). The mAb was undiluted, rabbit antiserum was diluted $1: 50$, and patient serum was undiluted, diluted $1: 10$ and $1: 100$. Prior to incubation, the rabbit antiserum was adsorbed with $E$. coli proteins. Prebleed rabbit serum, NS-1 supernatant and normal human serum were used as controls. The SPOTs peptides were treated according to the manufacturer's specifications (Genosys).

Ligand assay. The ligand assay was performed as recently described (Engbring \& Alderete, 1998). Assessment of binding efficiency was determined by ligand assay in which the amount of recombinant AP33 (rAP33), the total E. coli protein concentration and the volume involved in interaction with host cells were standardized. The amount of rAP33 was evaluated by immunoblot. Total $E$. coli protein concentration was determined by a bicinchoninic acid assay (BCA) according to the manufacturer (Pierce). The volume was adjusted to $2 \mathrm{ml}$ by addition of either control $E$. coli lysate or HEPES buffer.

Sequencing and computer analysis. DNA from all subclones was sequenced by the dideoxy chain-termination method (Sanger et al., 1977) using a Sequenase 2.0 DNA Sequencing kit (United States Biochemical). PC/GENE release 6.8 (IntelliGenetics) was used for all computer analyses.

Plasmid purification, PCR and transformants. Plasmid DNA was recovered using the Wizard Minipreps DNA Purification System (Promega) according to the manufacturer's specifications. The vectors containing HindIII fragments and PCR products were used in DNA sequencing described above. F5.3 was purified as recently described (Engbring \& Alderete, 1998). Primers were designed to generate a BamHI site on the $5^{\prime}$ end and an EcoRI site on the $3^{\prime}$ end of the subclones. Amplification was carried out, using purified F5.3 as a template, during 25 cycles of PCR with denaturation at $94{ }^{\circ} \mathrm{C}$ for $30 \mathrm{~s}$, annealing for $30 \mathrm{~s}$ at temperatures determined for the individual primers, and elongation at $68^{\circ} \mathrm{C}$ for $5 \mathrm{~min}$. The PCR products were purified using the Wizard PCR Preps DNA Purification System (Promega), digested with BamHI and EcoRI, re-purified, and ligated into the pcDNAII vector, which was then transformed into E. coli. Blue/white screening picked transformants, and insert sizes were examined on $1 \%$ agarose gels stained with ethidium bromide after the DNA had been digested with the indicated enzymes. The recombinant $E$. coli colonies were also replica-plated onto $\mu \mathrm{W}$ ave screening filters (Invitrogen) and grown at $37^{\circ} \mathrm{C}$ in the presence of IPTG for $3 \mathrm{~h}$ to induce rAP33 expression. These filters were processed for immunoblotting as specified by the manufacturer. Antibody-reactive clones were again checked by insert analysis.

Cytoadherence inhibition. A 25 -mer synthetic peptide consisting of the AP33 candidate binding domain and $\mathrm{mAb}$ epitope, as well as a random 25 -mer control peptide, were generated (Genosys). The peptides were resuspended at a

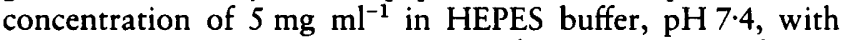
aliquots further diluted to $0.5 \mathrm{mg} \mathrm{ml}^{-1}$ and $0.25 \mathrm{mg} \mathrm{ml}^{-1}$. Pigheart SCS (Sigma) was likewise diluted, and $200 \mu$ l of each sample was added in triplicate to fixed monolayers of HeLa cells in 96-well plates, incubated at $37^{\circ} \mathrm{C}$ for $1 \mathrm{~h}$, and washed three times with PBS. A $100 \mu \mathrm{l}$ volume of TYM containing $4 \times 10^{5}$ metabolically radiolabelled trichomonads was added to each pretreated and three untreated wells for the $T$. vaginalis control, and incubated at $37^{\circ} \mathrm{C}$ for $30 \mathrm{~min}$. The wells were washed five times with PBS and the remaining radioactivity was determined by scintillation spectroscopy (c.p.m.). Percentage inhibition was calculated as $100-$ [(sample c.p.m. $/ T$. vaginalis control c.p.m.) $\times 100]$.

\section{RESULTS}

\section{Analysis of the CDNA clones}

The four cDNA clones corresponding to the third member of the AP33 family of proteins, AP33-3, included F5.1, F5.3, F5.4 and F5.6. Two of these, F5.3 and F5.4, were almost full-length, and since the reactivity of F5.3 was known, this clone was chosen to represent AP33-3. The other two were truncated at the $\mathrm{N}$-terminus, with F5.6 missing approximately one-quarter and F5.1 onehalf, when compared to AP33-3. These proteins were considered subclones, and were therefore renamed SC3.1 and SC3.2, respectively (Table 1). 
Table 1. Description of AP33-3 and subclones

\begin{tabular}{|c|c|c|c|c|}
\hline Clone & Source & $\begin{array}{l}\text { Size }^{*} \\
\text { (bp) } \\
\text { (aa) }\end{array}$ & $\begin{array}{c}\text { Position }+ \\
\text { (bp) } \\
\text { (aa) }\end{array}$ & $\begin{array}{c}\text { Mol. mass } \\
(\mathbf{k D a})^{*}\end{array}$ \\
\hline AP33-3‡ & & $\begin{array}{c}930 \\
309\end{array}$ & $\begin{array}{l}1-930 \\
1-309\end{array}$ & $32 \cdot 513$ \\
\hline F5.3 & $\mathrm{cDNA}$ & $\begin{array}{r}1008 \\
335\end{array}$ & $\begin{array}{c}37-930 \\
13-309\end{array}$ & 35.095 \\
\hline SC3.1 & $\mathrm{cDNA}$ & $\begin{array}{l}822 \\
274\end{array}$ & $\begin{array}{r}220-930 \\
74-309\end{array}$ & $28 \cdot 410$ \\
\hline SC3.2 & cDNA & $\begin{array}{c}564 \\
188\end{array}$ & $\begin{array}{r}478-930 \\
160-309\end{array}$ & 19.529 \\
\hline SC3.3 & PCR & $\begin{array}{c}432 \\
144\end{array}$ & $\begin{array}{l}628-930 \\
210-309\end{array}$ & $15 \cdot 189$ \\
\hline SC3.4 & PCR & $\begin{array}{c}957 \\
319\end{array}$ & $\begin{array}{c}28-900 \\
10-300\end{array}$ & 33.369 \\
\hline SC3.5 & PCR & $\begin{array}{l}756 \\
252\end{array}$ & $\begin{array}{c}28-699 \\
10-233\end{array}$ & $26 \cdot 538$ \\
\hline SC3.6 & PCR & $\begin{array}{c}507 \\
169\end{array}$ & $\begin{array}{c}478-900 \\
160-300\end{array}$ & $17 \cdot 377$ \\
\hline SC3.10 & PCR & $\begin{array}{c}534 \\
178\end{array}$ & $\begin{array}{c}28-477 \\
10-159\end{array}$ & 19.005 \\
\hline SC3.11S & PCR & $\begin{array}{c}594 \\
198\end{array}$ & $\begin{array}{c}385-594 \\
128-198\end{array}$ & $21 \cdot 253$ \\
\hline
\end{tabular}

* Size and molecular mass refer to fusion protein products, except for AP33-3. DNA includes coding regions only. The vector adds $114 \mathrm{bp} / 38$ residues $(4.03 \mathrm{kDa})$ for F5.3, SC3.1, SC3.2 and SC3.3, and $84 \mathrm{bp} / 28$ residues $(3.013 \mathrm{kDa})$ for the others.

† Position refers to the location relative to the start ATG/Met of the full-length AP33-3 gene or protein.

$\ddagger$ AP33-3 represents the full-length gene or protein without any fusion products.

\$One base missing at position 10 of the PCR product caused a frame-shift resulting in a fusion protein composed of the expected $\mathrm{N}$-terminal $\beta$-galactosidase fragment, a non-AP33-3 portion and an additional 99 amino acids encoded by the vector.

Expression levels and immunological reactivities of these proteins were checked. Fig. 1(a) demonstrates that each of the three recombinant proteins was overexpressed in E. coli. Importantly, the molecular masses coincided with those expected from fusion protein products (Table 1). An immunoblot of these proteins, as well as native $T$. vaginalis $\mathrm{AP} 33$, shows that the rabbit antiserum recognized F5.3 and SC3.1, but not SC3.2, indicating that the epitope(s) was in the N-terminal half of AP33 (Figs 1b and 2d). A duplicate immunoblot in Fig. 1(c) illustrates that the mAb detected all three clones, suggesting that the C-terminal half of AP33 contained this epitope (Fig. $2 \mathrm{~d})$. The ability of these proteins to bind to host cells was assessed by the ligand assay (see Methods). As demonstrated in Fig. 1(d), native T. vaginalis AP33, F5.3, as well as both subclones, bound to host cells, suggesting that at least one binding domain was located in the C-terminal half of AP33. As with all experiments, those shown in Fig. 1 were repeated at least three times with identical results.
The restriction enzyme HindIII cut the ap33 cDNA in two places, generating three potential subclones encoding amino acids $13-145,146-237$ and 238-309 (Fig. 2a). Although each of these fragments was placed into an expression vector, none was overexpressed, and this was later found to be due to the clones not being inframe with the coding sequence. However, enough protein was made, probably due to strand slippage, as detected by immunoblotting with both rabbit antiserum and $m A b$. The rabbit antiserum only recognized the 13-145 region, while the $\mathrm{mAb}$ recognized residues 146-237. These results narrowed down the epitopes for the antiserum to 72 amino acids $(74-145)$ and the $\mathrm{mAb}$ to 78 residues $(160-237)$.

\section{Analysis of PCR-generated subclones}

To further localize the functional areas of AP33, a series of deletion subclones was generated by PCR. Computer analyses for predicting the hydrophilicity, chain flexibility and surface accessibility were carried out for AP33-3. Areas with a high probability for all three properties were considered likely to be interactive, and are designated by the blackened peaks in Fig. 2(b). Interestingly, the most hydrophilic and flexible area overlapped and also had a good probability of being exposed on the parasite surface. Primers were designed to generate subclones either deleting or containing these regions, and the positions of the primers along ap 33 are shown in Fig. 2(c), with the resulting PCR-generated subclones described in Table 1, and depicted in Fig. 2(d). AP33 has a nine-amino-acid presequence that is cleaved (Fig. 2a, arrow) to produce the mature protein, and, therefore, this region was not included in any of the subclones. The PCR products were directionally ligated into the pcDNAII vector, which was then transformed into $E$. coli. The DNA was sequenced to verify that insertion, reading frame and PCR products were as expected.

Each of the subclones was tested for the presence of a linear epitope that was recognized by either the rabbit antiserum or the $\mathrm{mAb}$. This was carried out as described above, and the results are summarized in Fig. 2(e). Taken together with the reactivities of the cDNA and HindIII clones, an antiserum epitope still appeared to be contained within 72 residues in the $\mathrm{N}$-terminal half of AP33 (74-145), whereas the mAb epitope was localized to 28 amino acids in the C-terminal third (210-237).

The subclones were also examined for the ability to bind to host cells. A modified ligand assay described in Fig. 1(d) was carried out. However, both stained gels and immunoblots probed with both rabbit antiserum and the $\mathrm{mAb}$ were used to determine the protein bound to host cells. Surprisingly, all the subclones bound (Fig. 2e), including clones that had no overlapping residues (SC3.6 and SC3.10), indicating that more than one region was involved in adherence. As a negative control, one clone, SC3.11 (Table 1), was missing a base, resulting in a $21 \mathrm{kDa}$ fusion protein that did not follow the AP33 amino acid sequence. Importantly, this protein was 



Fig. 1. Expression levels, immunological reactivities and functional properties of three recombinant AP33 proteins. Equivalent amounts of $E$. coli proteins were separated by SDS-PAGE after equilibration of the cultures by optical density. Control denotes $E$. coli containing vector without insert DNA. AP33 is the native $T$. vaginalis adhesin enriched for by the ligand assay (see Methods). (a) Coomassie brilliant blue stained protein patterns of control and recombinant $E$. coli. Overexpressed recombinant proteins of different sizes are evident. (b) Duplicate gels shown in (a) and the natural AP33 after the ligand assay were blotted onto nitrocellulose prior to probing with rabbit antiserum. Prebleed serum did not detect these or any other proteins, and no proteins in control $E$. coli were recognized by the antiserum. (c) An immunoblot identical to that used in (b) was probed with mAb reactive with AP33. As a negative control, mAb of the same isotype failed to detect any proteins, and the AP33 mAb did not detect proteins in control $E$. coli. (d) Analysis of host cell binding by natural and recombinant AP33 proteins by the ligand assay. Extracts derived from French pressure fractionation of $E$. coli were used in the interaction assays. Following electrophoresis and blotting onto nitrocellulose, blots were probed with the AP33 mAb.

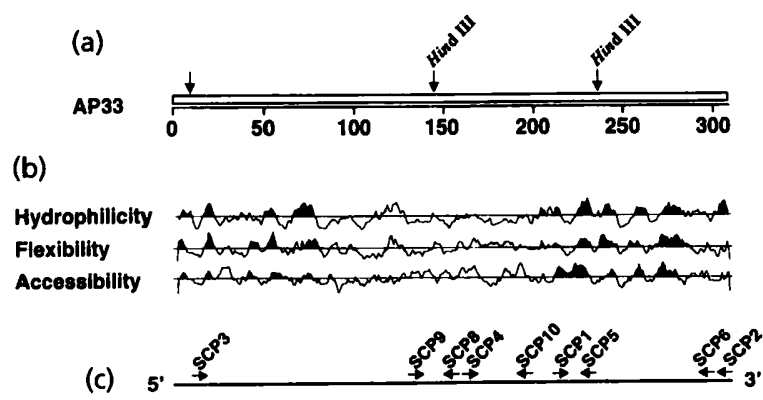

(d)

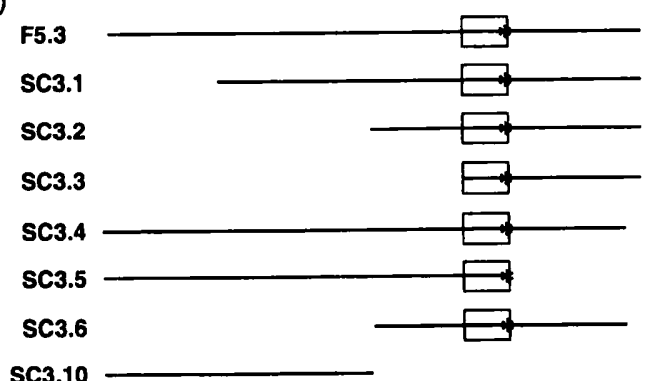

(e) R $\propto$ AP33 mAb Adherence

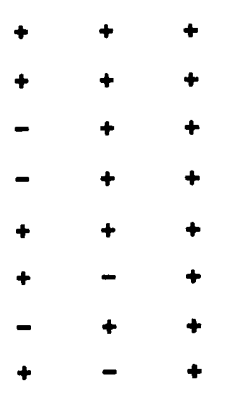

\begin{abstract}
Fig. 2. Generation of deletion subclones by PCR and analysis of properties for identification of functional domains. (a) Linear schematic representation of the AP33 protein with numbers referring to amino acids. The arrow signifies the leader peptide, and subclones derived from Hindill are indicated. (b) The predicted hydrophilicity, chain flexibility and surface accessibility of residues along AP33-3 are shown. Regions with a high probability of all three are presented as black peaks. (c) The positions of primers synthesized for generation of subclones by PCR. Arrows indicate the direction of DNA synthesis from each primer. (d) Sizes and positions of the three CDNA clones and of subclones derived by PCR. The boxed area designates 24 residues that are common to seven of these proteins. An asterisk represents the mAb epitope, which was determined by overlapping peptides shown in Fig. 4. (e) Summary of the immunoreactive and functional (adherence) properties of each subclone. $R \propto$ AP33, rabbit anti-AP33 serum.
\end{abstract}

overexpressed and readily visible in stained gels, but it was not detectable as a bound protein by the ligand assay, unlike the other subclones. Seven clones had 24 shared residues (Fig. 2d, boxed region), which corresponded to the predicted most interactive stretch of amino acids. Although each of the proteins containing this region bound to host cells, it was of interest to test whether they bound with equal efficiency, or if the apparent second binding domain influenced protein binding. Therefore, the ligand assay was performed with equivalent amounts of both total $E$. coli and recombinant AP33 (rAP33) proteins. The $\mathrm{mAb}$ was used to detect proteins that bound, and therefore SC3.5 and SC3.10 were not included. As shown in Fig. 3, each of the rAP33 proteins appeared to bind with equal efficiency. The amount of SC3.6 present in the French press lysate was much less than the other clones and, even if undiluted, could not be equilibrated within the 


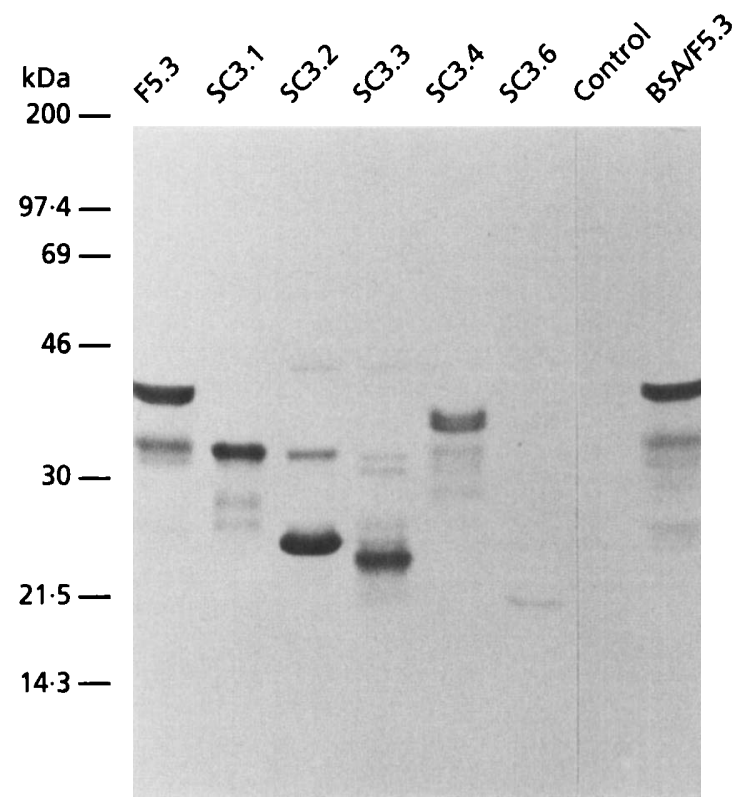

Fig. 3. Binding by the rAP33 proteins as demonstrated by the ligand assay. The amount of the rAP33 proteins used in the ligand assay was adjusted based on band intensity with the $\mathrm{mAb}$ after electrophoresis and immunoblotting as performed for Fig. 1(d). Total protein concentration was adjusted to yield equal concentration and volume by adding control $E$. coli lysate and/or buffer. The ligand assay, described in Fig. 1(d), was performed with the equilibrated lysates. Control refers to $E$. coli containing vector without insert. The extract of subclone SC3.6 had less recombinant protein compared to the other subclones and was used as a control. Also, addition of BSA to $E$. coli extract of clone F5.3 did not affect the level of protein bound to host cells.

volume used for the others. The immunoblot after the ligand assay shows that the amount of recombinant proteins bound to host cells mirrored the amount used in the experiment. Interestingly, when BSA was added to the lysate with F5.3 to double the total protein concentration, binding of F5.3 (Fig. 3, BSA/F5.3 lane) was unaffected by the extraneous protein. These results illustrate the ability of all these subclones to recognize and bind to sites on HeLa cell surfaces.

\section{Identification of the mAb epitope}

The $\mathrm{mAb}$ recognized clones that had 28 amino acids in common, suggesting that the epitope was within this region. Interestingly, this area also encompassed the 24 amino acids implicated as important to a binding domain, since this region was common to seven of the eight subclones that bound. Therefore, overlapping decapeptides, including and slightly surrounding the potential receptor-binding domain, were generated (SPOTs, Genosys) and tested for mAb reactivity. Two of the peptides were recognized by the $\mathrm{mAb}$, indicating that this epitope consisted of nine amino acids (Fig. 4). Not surprisingly, these residues included six that were predicted to be the most antigenic, on the most flexible part of the amino acid chain, as well as surface accessible (Fig. 2b). Interestingly, removal of one of the epitope amino acids abolished $\mathrm{mAb}$ reactivity since $\mathrm{SC} 3.5$ was not recognized, although it included eight of the epitope amino acids, confirming the SPOTs data.

\section{Identification of a binding domain}

A synthetic peptide of the 24-residue candidate binding domain plus the additional $\mathrm{mAb}$ epitope residue (Fig. 4) was tested for the ability to inhibit $T$. vaginalis cytoadherence. Fixed host-cell monolayers were pretreated with either this peptide, a random control peptide of equal length, or SCS in concentrations ranging from $50 \mu \mathrm{g}$ to $1 \mathrm{mg}$ in the wells of the adherence assay as described in Methods. Metabolically radiolabelled $T$. vaginalis organisms were then incubated with either the pretreated or untreated cells. Binding was measured by scintillation spectroscopy and reflected the number of parasites bound to host cells. The amount of radioactivity in control untreated cell monolayer wells was considered $0 \%$ cytoadherence inhibition, and comparisons with pretreated monolayers represented the percentage inhibition. Only the binding domain peptide inhibited cytoadherence in a concentration-dependent manner, with $40 \%, 30 \%$ and $4 \%$ inhibition as the amount of peptide used for pretreatment was decreased (Fig. 5). Not unexpectedly, the control peptide was without effect, and SCS inhibited minimally. This experiment was performed numerous times with similar results; only the experimental peptide, but not the control peptide or SCS enzyme, inhibited cytoadherence.

\section{DISCUSSION}

This report presents localization of antigenic and adhesive regions on AP33 identified by the examination of deletion subclones. Two immunoreactive areas of AP33 were found. The rabbit antiserum generated against AP33 recognized a site(s) within 72 residues (74-145) in the $\mathrm{N}$-terminal half of the protein. Interestingly, IgG purified from this antiserum was previously shown, by indirect immunofluorescence, to detect the surface of T. vaginalis (Arroyo et al., 1992; Engbring \& Alderete, 1998). This indicates that an antiserumreactive epitope on AP33 is accessible on live organisms; however, the residues that are involved have not yet been precisely delineated. By the use of overlapping decapeptides, the $\mathrm{mAb}$ epitope was identified as nine amino acids (226-234) in the C-terminal third of AP33. Although the $\mathrm{mAb}$, which recognized a portion of the $\mathrm{C}$ terminal binding domain, detected trichomonads by indirect immunofluorescence, a weak reactivity of live parasites (Arroyo et al., 1993) also paralleled poor cytoadherence inhibition (R. Arroyo, unpublished observations), consistent with the earlier notion that this site is marginally accessible on live organisms, possibly due to the dynamics of protein conformation.

The ligand assay results using subclones suggested at least two separate areas of AP33 are involved in binding. 


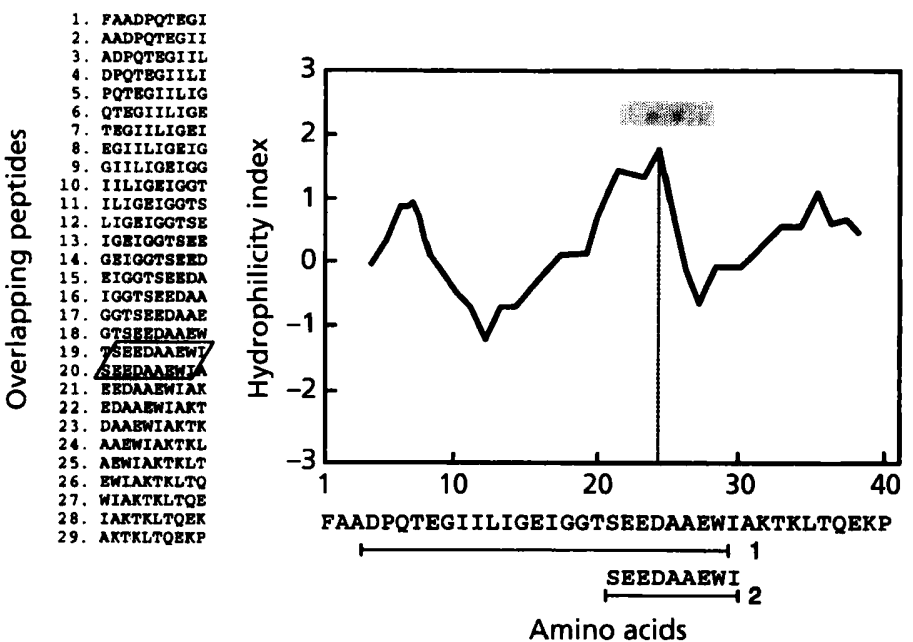

Amino acids
Fig. 4. Identification of the mAb epitope. A series of overlapping decapeptides spanning 38 residues was probed with the mAb. Peptides 19 and 20, corresponding to the highest hydrophilicity peak, were immunoreactive as shown by the spot intensities above the peak. Little or no detection of peptide 21 is evident. Line 1 below the graph includes the receptorbinding domain used for cytoadherence inhibition experiments (Fig. 5), and line 2 shows the mAb epitope overlapping the binding domain.

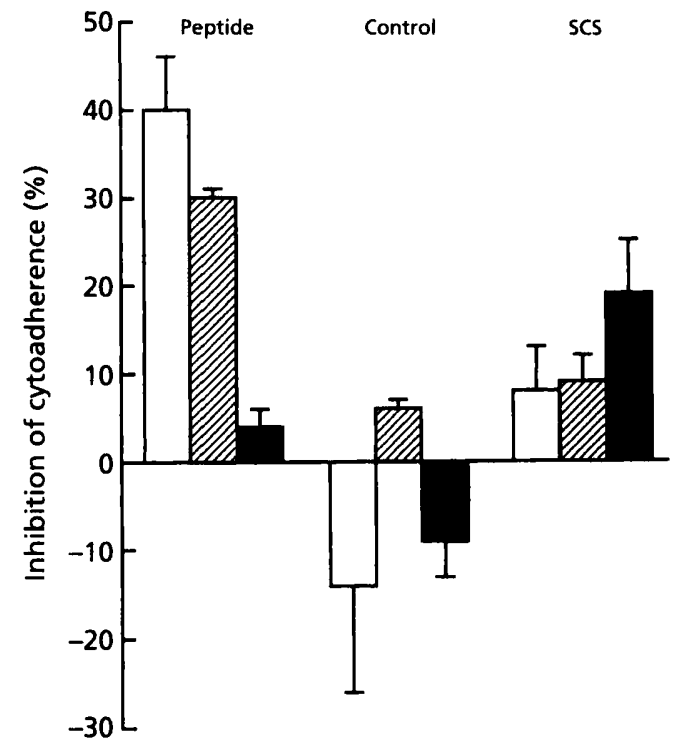

Fig. 5. Effect of a 25-mer synthetic peptide containing the candidate binding domain (Fig. 4) on inhibiting cytoadherence of $T$. vaginalis. The host cell attachment assay and calculation of the percentage inhibition are described in Methods. A control peptide of the same size and excess amounts of purified SCS were used for comparative purposes. Amount of peptide used: $1 \mathrm{mg}(\square) ; 100 \mu \mathrm{g}($ 圆); $50 \mu \mathrm{g}(\square)$.

One of the regions was in the N-terminal half of AP33. Importantly, the rabbit antiserum epitope was within this region, and IgG purified from the antiserum has been shown to be effective at inhibiting cytoadherence (Arroyo et al., 1992). This prompted an evaluation of other portions of AP33, such as those within the Cterminus, also contributing to cytoadherence. The other area implicated in binding was localized to 24 amino acids (210-233) in the C-terminal third of AP33. It is not insignificant that a synthetic peptide of this sequence inhibited cytoadherence by $40 \%$, especially considering that there are three other adhesins involved in optimal host cell binding (Alderete \& Garza, 1988; Arroyo et al., 1992).

Recent reports describe proteins with multiple interactive domains, including sites that mediate binding to the same or separate parts of a protein, or even to distinct proteins. For instance, protein $\mathrm{F}$ of group A Streptococcus contains two fibronectin-binding domains that are independently capable of adherence, and, interestingly, are directed at the same host receptor (Ozeri et al., 1996). Furthermore, protein $\mathrm{F}$ has also recently been found to bind to fibrinogen (Katerov et al., 1998). It was suggested this would give the bacteria an advantage for successful adherence since there may be competition between micro-organisms and other host molecules for a limited number of binding sites on fibronectin. Fimbrillin of Porphyromonas gingivalis has been proposed to have at least three binding sites for salivary proteins, and the combination of these sites may be required to establish stable bacterial adherence (Amano et al., 1996). Finally, the multiple domains of the $\mathrm{N}$-formyl peptide receptor on phagocytes are believed to be necessary for high-affinity ligand binding (Quehenberger et al., 1993).

AP33 has homology to $\alpha$-SCS (Engbring \& Alderete, 1998; Lahti et al., 1994), and although the enzyme did not affect cytoadherence, it was important to compare the amino acid sequences within the putative binding domain. The C-terminal cell-binding domain was predicted to be interactive based on the hydrophilicity and chain flexibility profiles (Fig. 2b). The degree of identity within this region and $\alpha$-SCS of three other organisms (i.e. E. coli, Haemophilus influenzae and Thermophilus flavus) and the rat sequences was high, ranging from 63 to $75 \%$. Furthermore, one of four conserved sequences important for enzyme activity was contained within the binding domain. The $\mathrm{mAb}$ epitope overlapped the binding domain, but not the conserved region, and identity within this area was found to be $56 \%$ for the micro-organisms and the rat. However, the mAb did not recognize $E$. coli, $T h$. flavus or pig-heart $\alpha$-SCS, possibly 
due to altered conformation at this epitope site. Finally, it may be significant that serum from ten different patients failed to recognize AP33 (data not shown), although other proteins in a total T. vaginalis protein profile were detected (Alderete et al., 1985, 1992).

The ultimate goal of studying adhesins is to be able to affect $T$. vaginalis pathogenesis by interfering with the adherence process. However, AP33 homology to the $\alpha$ subunit of the metabolic enzyme SCS must not be ignored. Molecular mimicry, the sharing of antigenic determinants between parasite and host, was typically thought to have a threefold outcome: immune evasion, autoimmunity and the development of host antigenic polymorphisms. Despite the $\mathrm{mAb}$ epitope being predicted to be the most antigenic part of AP33, and having an identity of $56 \%$ with this region of $\alpha$-SCS of other organisms, the $\mathrm{mAb}$ did not recognize the pig-heart, $E$. coli or $T h$. flavus enzyme subunit as determined by immuno-cross-reactivity. However, even though there are complicating factors in the host-parasite immune response, such as $T$. vaginalis Ig-degrading proteinases (Provenzano \& Alderete, 1995), there is no evidence that female patients mount an effective humoral immune response against this organism, and, accordingly, serum from ten patients did not recognize AP33. Therefore, it is possible that potentially antigenic regions of AP33 are more correctly viewed as eclipsed mimetic epitopes, sites that are hidden from host immune recognition (Damian, 1989). The term molecular mimicry was later broadened to include other functional relationships involving similar or shared molecular structures (Damian, 1989). Clearly, there is structural mimicry of AP33 to host $\alpha$ SCS at all levels. For instance, one of the four $\alpha$-SCS consensus sequences is within the 24-residue putative Cterminal binding domain. This site includes an acidic residue implicated in binding $\mathrm{Mg}^{2+}$, a cofactor for the enzyme. However, divalent cations have frequently been shown to be involved in adherence (Smith, 1994), and it is possible that this is an important component in $T$. vaginalis binding to host cells. In addition, it is now a relatively common occurrence to find enzymes on microbial surfaces where they act as binding proteins, as reported previously (Alderete et al., 1995; Engbring et al., 1996; Engbring \& Alderete, 1998). Further analysis of the functional domains of the T. vaginalis AP33 adhesin should provide a better understanding of the relationship between the enzyme and the adhesin, as well as interactions of regions of the adhesin with each. This work will hopefully help us understand the molecular mechanisms of host parasitism.

\section{ACKNOWLEDGEMENTS}

This work was supported by Public Health Service through a grant from the National Institutes of Health. J.A.E. was funded, in part, through an NIH training grant.

\section{REFERENCES}

Alderete, J. F. \& Garza, W. E. (1988). Identification and properties of Trichomonas vaginalis proteins involved in cytoadherence. Infect Immun 56, 28-33.
Alderete, J. F., Suprun-Brown, L., Kasmala, L., Smith, J. \& Spence, M. (1985). Heterogeneity of Trichomonas vaginalis and discrimination among trichomonal isolates and subpopulations by sera of patients and experimentally infected mice. Infect Immun 49, 463-468.

Alderete, J. F., Newton, E., Dennis, C. \& Neale, K. A. (1992). The vagina of women infected with Trichomonas vaginalis has numerous proteinases and antibody to trichomonad proteinases. Genitourin Med 67, 469-474.

Alderete, J. F., O'Brien, J. L., Arroyo, R., Engbring, J. A., Musatovova, O., Lopez, O., Lauriano, C. \& Nguyen, J. (1995). Cloning and molecular characterization of two genes encoding adhesion proteins involved in Trichomonas vaginalis cytoadherence. $\mathrm{Mol}$ Microbiol 17, 69-83.

Alderete, J. F., Engbring, J., Lauriano, C. \& O'Brien, J. (1998). Only two of the Trichomonas vaginalis triplet AP51 adhesins are regulated by iron. Microb Pathog 24, 1-16.

Amano, A., Sharma, A., Lee, J. Y., Sojar, H. T., Raj, P. A. \& Genco, R. J. (1996). Structural domains of Porphyromonas gingivalis recombinant fimbrillin that mediate binding to salivary prolinerich protein and statherin. Infect Immun 64, 631-637.

Arroyo, R. \& Alderete, J. F. (1989). Trichomonas vaginalis surface proteinase activity is necessary for parasite adherence to epithelial cells. Infect Immun 57, 2991-2997.

Arroyo, R., Engbring, J. \& Alderete, J. F. (1992). Molecular basis of host cell epithelial cell recognition by Trichomonas vaginalis. Mol Microbiol 6, 853-862.

Arroyo, R., Gonzalez-Robles, A., Martinez-Palomo, A. \& Alderete, J. F. (1993). Signaling of Trichomonas vaginalis for amoeboid transformation and adhesin synthesis follows cytoadherence. Mol Microbiol 7, 299-309.

Arroyo, R., Engbring, J., Nguyen, J., Musatovova, O., Lopez, O., Lauriano, C. \& Alderete, J. F. (1995). Characterization of cDNAs encoding adhesin proteins involved in Trichomonas vaginalis cytoadherence. Arch Med Res 26, 361-369.

Damian, R. T. (1989). Molecular mimicry: parasite evasion and host defense. Curr Top Microbiol Immunol 145, 101-115.

Diamond, L. S. (1957). The establishment of various trichomonads of animals and man in axenic cultures. J Parasitol 43, 488-490.

Engbring, J. A. \& Alderete, J. F. (1998). Three genes encode distinct AP33 proteins involved in Trichomonas vaginalis cytoadherence. Mol Microbiol 28, 305-313.

Engbring, J. A., O'Brien, J. \& Alderete, J. F. (1996). Trichomonas vaginalis adhesin proteins display molecular mimicry to metabolic enzymes. Adv Exp Med Biol 408, 207-223.

Katerov, V., Andreev, A., Schalen, C. \& Totolian, A. A. (1998). Protein F, a fibronectin-binding protein of Streptococcus pyogenes, also binds human fibrinogen: isolation of the protein and mapping of the binding region. Microbiology 144, 119-126.

Krieger, J. N., Verdon, M., Siegel, N. \& Holmes, K. K. (1993). Natural history of urogenital trichomoniasis in men. J Urol 149, 1455-1458.

Laemmli, U. K. (1970). Cleavage of structural proteins during assembly of the head of bacteriophage T4. Nature 277, 680-685.

Lahti, C. J., Bradley, P. J. \& Johnson, P. J. (1994). Molecular characterization of the $\alpha$-subunit of Trichomonas vaginalis hydrogenosomal succinyl-CoA synthetase. Mol Biochem Parasitol 66, 309-318.

Müler, M., Meingassner, J. G., Miller, M. A. \& Ledger, W. J. (1980). Three metronidazole-resistant strains of Trichomonas vaginalis from the USA. Am J Obstet Gynecol 138, 808-812. 
Ozeri, V., Tovi, A., Burstein, I., Natanson-Yaron, S., Caparon, G., Yamada, K., Akiyama, S. K., Vlodavsky, I. \& Hanski, E. (1996). A two-domain mechanism for group A streptococcal adherence through protein $\mathrm{F}$ to the extracellular matrix. EMBO $J \mathbf{1 5}$, 989-998.

Provenzano, D. \& Alderete, J.F. (1995). Analysis of human immunoglobulin-degrading cysteine proteinases of Trichomonas vaginalis. Infect Immun 63, 3388-3395.

Quehenberger, O., Prossnits, E. R., Cavanah, S. L., Cochrane, C. G. \& Ye, R. D. (1993). Multiple domains of the $N$-formyl peptide receptor are required for high-affinity ligand binding. J Biol Chem 268, 18167-18175.

Quinn, T. C. \& Krieger, J. N. (1990). Trichomoniasis. In Tropical and Geographic Medicine, 2nd edn, pp. 358-365. Edited by K. S. Warren \& A. A. F. Mahmoud. New York: McGraw-Hill.

Sambrook, J., Fritsch, E. F. \& Maniatis, T. (1989). Molecular Cloning: a Laboratory Manual, 2nd edn. Cold Spring Harbor, NY: Cold Spring Harbor Laboratory.
Sanger, F., Nicklen, S. \& Coulson, A. R. (1977). DNA sequencing with chain terminating inhibitors. Proc Natl Acad Sci USA 74, 5463-5467.

Smith, J. W. (1994). The structural basis of integrin-ligand (RGD) interaction. In Integrins Molecular and Biological Responses to the Extracellular Matrix, pp. 1-31. Edited by D. A. Cheresh \& R. P. Mecham. San Diego: Academic Press.

Towbin, H., Staehelin, T. \& Gordon, J. (1979). Electrophoretic transfer of proteins from polyacrylamide gels to nitrocellulose sheets : procedure and some applications. Proc Natl Acad Sci USA 76, 4350-4354.

World Health Organization (1995). An overview of selected curable sexually transmitted diseases. WHO Global Programme on AIDS Report.

Received 18 May 1998; revised 15 July 1998; accepted 27 July 1998. 